\title{
Rancangan Multimedia \\ Tari Kreasi Anak "Oray-orayan" Untuk Pembelajaran SBdP di Sekolah Dasar
}

\author{
Khaerunnisa Sri Wahyuni ${ }^{1}$, Aan Kusdiana ${ }^{2}$, dan Oyon Haki Pranata ${ }^{3}$ \\ Program Studi S1 Pendidikan Guru Sekolah Dasar \\ Universitas Pendidikan Indonesia Kampus Tasikmalaya \\ Jalan Dadaha No. 18 Kota Tasikmalaya 46115 \\ Tlp.0265-331860,E-mail: kampus_tasikmalaya@upi.edu
}

\begin{abstract}
RINGKASAN
Penelitian yang dilakukan ini dilatarbelakangi oleh pentingnya rancangan multimedia tari pada pembelajaran SBdP. Penelitian ini bertujuan untuk mendeskripsikan hasil dan bentuk rencana multimedia tari kreasi anak "oray-orayan" untuk pembelajaran SBdP di Sekolah Dasar. Dalam pembelajaran SBdP, media pembelajaran yang digunakan berupa video dari internet. Video tersebut masih sederhana didalamnya hanya berupa gerakan tari, tidak terdapat animasi gerak tari dengan menggunakan tokoh kartun, tidak ada langkah-langkah menari serta tidak terdapat gambar dan teks sebagai materi pendukung. Media pembelajaran ini termasuk hal penting dalam proses pembelajaran, karena sebagai alat perantara dalam proses pembelajaran yang digunakan untuk menyampaikan informasi dalam proses pembelajaran antara guru terhadap peserta didik dalam menyampaikan informasi. Diharapkan dapat menciptakan pembelajaran yang lebih bermakna dengan pengembangan yang dilakukan terhadap salah satu media pembelajaran. Penelitian ini menggunakan metode kualitatif dengan analisis data secara deskriptif dengan menggunakan data hasil FGD (Focus Group Discuss). berdasarkan data FGD yang di dapatkan, rancangan Multimedia Tari Kreasi Anak "Oray-orayan" mendapatkan kelayakan dan memenuhi kriteria yang diinginkan untuk dijadikan sebagai media pembelajaran yang dapat digunakan untuk pembelajaran SBDP di SD.
\end{abstract}

Kata kunci: Multimedia, Tari Kreasi Anak, oray-orayan, pembelajaran SBdP

\begin{abstract}
This Research is backed the importance of multimedia design dance on SBdP learning. This research aims to describe the results and form of multimedia plan of childern Dance Creations "Oray-orayan" for learning SBdP in elemntary school. In SBdP learning, the learning media used is video from the Internet. The Video is still simple in the form of dance movement, there is no animation of dance motion using cartoon characters, there are no dance steps and there are no pictures and texts as supporting material. This learning Media is important in the learning process, because as an intermediate tool in the learning process used to convey information in the learning process between teachers and students in conveying information. It is hoped that you can create more meaningful learning with the development done with one of the learning media. This research uses qualitative methods with descriptive data analysis using FGD (Focus Group Discuss)result data. Based on the FGD data obtained, the Multimedia design of the children's Dance creations "OrayOrayan" is qualified and fulfills criteria which is desirable to serve as a learning medium that can be used to study SBdP in SD.
\end{abstract}

Keywords: Multimedia, Children's Creative Dance, oray-Orayan, SBDP learning 


\section{PENDAHULUAN}

Belajar dapat diartikan sebagai penambahan, perluasan dan pendalaman pengetahuan, nilai dan sikap serta keterampilan. Pada hakikatnya belajar adalah suatu proses interaksi terjadi pada suatu lingkungan. Belajar dapat juga dipandang sebagai proses yang diarahkan untuk mencapai suatu tujuan dalam pengembangan individu. Sebagaimana definisi belajar menurut Катиs Besar Bahasa Indonesia (KBBI) bahwa belajar adalah berusaha memperoleh proses pembelajaran sangat berperan penting dalam pencapaian tujuan pembelajaran. Pendidik diharuskan memiliki kualifikasi baik dalam menjalankan profesinya, salah satunya adalah kompetensi pendidik. Kompetensi pendidik merupakan seperangkat pengetahuan, keterampilan, dan perilaku yang dimiliki dan dikuasai oleh seorang pendidik dalam melaksanakan keprofesionalannya, melakukan perencanaan pembelajaran menjadi langkah dalam menentukan berhasil tidaknya suatu proses pembelajaran. Dalam merencanakan pembelajaran perlu diperhatikan dua unsur penting yaitu metode pembelajaran dan media pembelajaran yang akan digunakan untuk mendukung pemahaman materi pelajaran oleh peserta didik. Kedua unsur tersebut saling berkaitan. Penggunaan salah satu metode pembelajaran tertentu akan kepandaian atau ilmu, berlatih, berubah tingkah laku atau tanggapan yang disebabkan pengalaman. Kelangsungan proses interaksi yang bersifat edukatif antara guru dan peserta didik terjadi dalam proses pembelajaran. Dalam proses pembelajaran, dibutuhkan komponen-komponen pendukung yang membantu keberhasilan suatu proses pembelajaran. Pendidik merupakan salah satu ujung tombak terlaksananya

mempengaruhi pemilihan jenis media pengajaran yang sesuai dengan metode pembelajaran yang dipilih.

Media pembelajaran yang digunakan adalah multimedia. Multimedia merupakan perpaduan antara berbagai media (format file) berupa teks, gambar (vektor atau bitmap), grafik, sound, animasi, video, interaksi dan lain-lain yang telah dikemas menjadi file digital (komputerisasi), digunakan untuk menyampaikan pesan kepada publik (Munir, 2015, hlm. 2). Penggunaan multimedia dalam pembelajaran dapat memacu indra pendengaran dan indra penglihatan secara bersamaan, sehingga akan menarik perhatian siswa untuk belajar. Dengan menggunakan multimedia akan memudahkan peserta didik dalam belajar. Sebagimana mengacu pada pendapat Ashyar (2011, hal. 8) bahwa 
multimedia dapat membantu pendidik menjelaskan isi pelajaran kepada peserta didik, menghemat waktu dan meningkatkan motivasi peserta didik dalam belajar.

Salah satu mata pelajaran yang memerlukan media adalah Seni Budaya dan Prakarya (SBdP). Seni Budaya dan Prakarya (SBdP) di Sekolah Dasar terintegrasi dengan mata pelajaran lain dalam pelajaran tematik. Pelajaran Seni Budaya dan Prakarya (SBdP) sebagai salah satu pelajaran diajarkan di Sekolah Dasar, di dalamnya memuat seni tari, seni musik, seni rupa dan keterampilan. Kompetensi ini (KI) dan Kompetensi Dasar (KD) merupakan dasar pijakan menuju pengembangan media pembelajaran. Cakupan KI dan KD dalam kurikulum 2013, kelas IV Sekolah Dasar cabang seni tari yaitu:

KI 3 : Memahami pengetahuan faktual dengan cara mengamati (mendengar, melihat, membaca) dan menanya berdasarkan rasa ingin tahu tentang dirinya, makhluk ciptaan Tuhan dan kegiatannya dan benda-benda yang dijumpainya di rumah dan di sekolah.

KD 3.3Mengetahui gerak tari kreasi daerah.

KI 4 : Menyajikan pengetahuan faktual dalam bahasa yang jelas, sistematis dan logis, dalam karya yang estetis, dalam gerakan yang mencerminkan anak sehat dan dalam tindakan yang mencerminkan perilaku anak beriman dan berakhlak mulia.

KD 4.3 Meragakan gerak tari kreasi daerah. Pengembangan pembelajaran Kurikulum 2013 pada mata pelajaran Seni Budaya dan Prakarya (SBdP) lebih menekankan pada kreativitas. Pembelajaran bukan sekedar proses transformasi pengetahuan tetapi perlu diupayakan pengembangan sikap secara aktif, kritis, dan kreatif yang dapat merangsang kemampuan berpikir, mengembangkan nilai keindahan, serta mempunyai kemampuan menghargai karya seninya (Lestari Asti Tri, 2017).

Pelajaran SBdP tujuannya memberikan pengalaman estetik pada peserta didik dalam bentuk kegiatan berekpresi/berkreasi dan berprestasi. Hasil pembelajaran Seni Budaya dan Prakarya (SBdP) diharapkan membentuk pribadi peserta didik harmonis dan memiliki multi kecerdasan agar mampu mengembangkan bakat dan kreativitasnya sesuai dengan pilihan dengan potensi diri yang dimiliki para peserta didik. Tujuan akhir pendidikan Seni Budaya dan Prakarya (SBdP) tidak hanya menciptakan peserta didik cerdas tetapi juga peserta didik yang jujur, bertanggung jawab, dan peduli terhadap sesama. Salah satu materi Seni Budaya dan Prakarya (SBdP) di Sekolah Dasar yaitu tari kreasi.

Tari kreasi pada mata pelajaran Seni Budaya dan Prakarya (SBdP) merupakan 
materi digunakan untuk memberikan nilai positif bagi peserta didik dalam pendidikan tari. Peran pendidik dalam pembelajaran tari yaitu harus memahami suatu konsep untuk mendidik peserta didik dalam aktivitas seni. Namun pada kenyataannya implementasi kurikulum 2013 di lapangan khususnya kurikulum pendidikan seni tari di Sekolah Dasar nampaknya masih memerlukan pembenahan. Kompetensi pendidik kurang memahami makna sebuah pendidikan seni tari di Sekolah Dasar turut pula memberikan dampak terhadap hasil pembelajaran. Pendidik Sekolah Dasar adalah pendidik bukan khusus mengajarkan seni tari, maka harus memahami bahwa pendidikan seni tari yang diterapkan dalam pembelajaran intra kurikuler, peserta didik bukan dipaksakan untuk bisa menari, melainkan menumbuhkan kreatifitas tari pada diri peserta didik itu sendiri, karena pada kegiatan intra kurikuler, minat dan bakat peserta didik beraneka ragam.

Menurut Sedyawati (2010:307) dalam Lestari Asti Tri (2017), untuk menghidupkan dan mengembangkan kemampuan kreatifitas, pendidik perlu menguasai berbagai teknik di antaranya:

1. Khasanah teknik seni untuk dipraktikkan.

2. Teknik-teknik rangsangan untuk menimbulkan kepercayaan dan kemudian kemampuan mengekspresikan suatu ide seni.
3. Teknik rangsangan untuk menghidupkan daya imajinasi dan kreativitas.

Teknik di atas digunakan untuk memberikan pengetahuan, melatih kreativitas peserta didik untuk mengekspresikan seni dalam gerak, peka terhadap seni dan sosial untuk memberikan wawasan budaya secara menyeluruh.

Dalam pemahaman kreativitas seni tari, pendidik atau peserta didik harus mampu menciptakan, memadukan atau mengkombinasikan gerak tari dengan aspek kehidupan di dunia nyata. Aspek kehidupan tersebut di antaranya kehidupan antar manusia, kehidupan flora dan fauna serta kehidupan manusia dengan alam lingkungannya. Berkaitan dengan hal tersebut maka untuk menciptakan gerak tari kreasi anak dalam kehidupan antar sesama manusia salah satunya adalah oray-orayan".

Oray-orayaan merupakan permainan tradisional di Jawa Barat. Pola permainan dasarnya adalah kepala ular menangkap ekor ular, puncak permainannya adalah kepala ular berhasil menangkap/memakan ekornya sendiri. Ditinjau dari lagunya permainan ini dapat melatih kepekaan musikalitas dan aspek motorik anak. Sedangkan ditinjau dari gerak dan sosial, terdapat nilai-nilai karakter seperti sikap gotong royong, setia kawan, sportif, saling menolong, saling menghargai, melatih berpikir cerdas, tekun, dan kreatif (Giyartini 
JOGED

ISSN: $1858-3989$

Rosarina, 2014).

\section{Metode Penelitian}

Penelitian ini menggunakan metode kualitatif, untuk memahami fenomena tentang yang dialami subjek penelitian secara holistik dalam suatu konteks alamiah dan dengan memanfaatkan berbagai metode alamiah (Moleong, 2017).

Analisis data diungkapkan secara deskriptif dengan maksud untuk menggambarkan hasil dan bentuk rancangan Multimedia Tari Kreasi Anak "Oray-orayan" untuk pembelajaran SBdP di Sekolah Dasar.

Sasaran penelitian ini diperoleh subjek data dari 25 orang peserta didik Sekolah Dasar. Semua peserta didik belajar bersama dengan guru menggunakan video pembelajaran tari kreasi anak "oray-orayan".

Dengan menggunakan data dari hasil FGD (Focus Group Discuss) analisis data yang diungkapkan menggunakan metode content analisis atau analisis isi dari hasil pengumpulan data. Data diambil dari FGD yang dilakukan oleh satu tim yang berfokus untuk mendiskusikan bagaimana rancangan Multimedia Tari Kreasi Anak "Oray-orayan" untuk pembelajaran SBdP di Sekolah Dasar. Setelah proses FGD dilakukan proses Validasi ahli media.

Proses yang dilakukan saat FGD dapat dilihat pada Gambar 1.

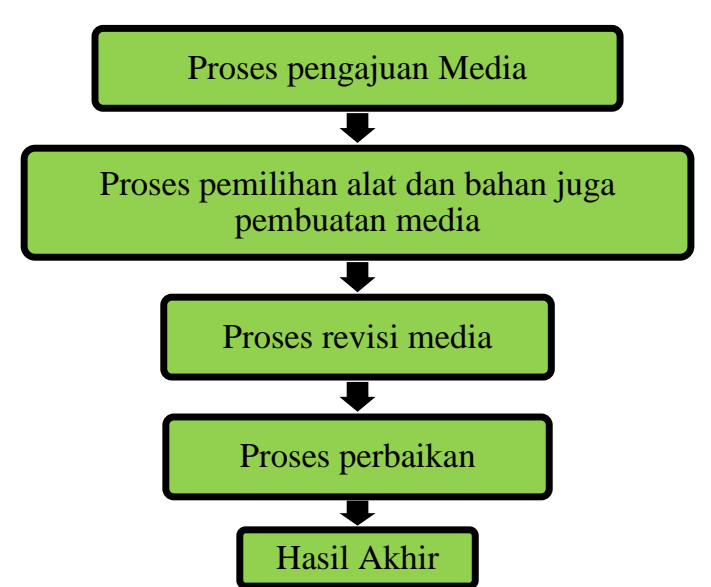

Gambar 1. Proses FGD yang dilakukan peneliti

Pada Gambar 1 dapat dijelaskan Proses FGD yang dilakukan setelah mengajukan media yang akan menjadi fokus FGD. Media yang diajukan adalah Multimedia Tari Kreasi Anak "Oray-orayan". Media diajukan setelah mengkaji kurikulum yang dihubungkan dengan Pembelajaran SBdP yang dikaitkan dengan tema pembelajaran pada pembelajaran tematik kurikulum 2013.

Setelah dilakukannya proses pengajuan media dilakukan pemilihan alat dan bahan yang akan digunakan ketika pembuatan media. Setelah itu media diuji dengan tim yang nantinya akan dilakukan revisi. Setelah dilakukan revisi media diperbaiki. Setelah itu didapatkan hasil akhir media berupa hasil perbaikan sesuai dengan pembelajaran SBdP kurikulum 2013. 


\section{PEMBAHASAN}

Hasil dari data FGD yang dilakukan, menyatakan bahwa: Multimedia Tari Kreasi Anak "Oray-orayan" merupakan media pembelajaran yang dirancang dengan memperhatikan berbagai aspek pembelajaran di Sekolah Dasar yang disesuaikan dengan pembelajaran kurikulum 2013. (Trianto, 2010) "Pembelajaran tematik dimaknai sebagai pembelajaran yang dirancang berdasarkan tema-tema tertentu dalam pembahasannya tema itu ditinjau dari berbagai mata pelajaran".

Multimedia Tari Kreasi Anak "Orayorayan" sangat berpeluang untuk dijadikan sebagai bentuk pengembangan media pembelajaran SBdP yang dirancang sesuai dengan Kompetensi Dasar di Sekolah Dasar.

Media pembelajaran yang akan dibuat ini secara konkrit berupa multimedia, yang memiliki komponen penting, di antaranya sebagai berikut:

\section{Teks}

Teks digunakan untuk menjelaskan gambar yang ada dalam multimedia karena Teks tentu saja tidak bisa dipisahkan dalam penggunaan komputer. Sebagaimana menurut Munir (2012, hlm. 20) yakni "Teks adalah suatu kombinasi huruf yang membentuk satu kata atau kalimat yang menjelaskan suatu maksud atau materi pembelajaran yang dapat dipahami oleh orang yang membacanya". Teks dapat membentuk kata atau narasi dalam multimedia yang menyajikan bahasa. Kebutuhan teks bergantung kepada penggunaan aplikasi multimedia. Penggunaan teks pada multimedia perlu memperhatikan penggunaan jenis huruf, ukuran huruf, spasi, dan style hurufnya (warna, bold, italic).

\section{Grafik}

Grafik adalah lukisan pasang surut suatu keadaan dengan garis atau gambar. Munir (2012, hlm. 20) menjelaskan bahwa "Grafik merupakan komponen penting dalam multimedia. Grafik berarti juga gambar (image, picture, atau drawing)." Grafik merupakan komponen penting multimedia, sama halnya dengan media gambar karena manusia berorientasi pada visual, sehingga informasi yang menggunakan gambar, animasi dan video lebih mudah dicerna dibandingkan dengan informasi dalam bentuk teks.

3. Gambar

Gambar digunakan dalam penyajian multimedia karena lebih menarik perhatian dan dapat mengurangi kebosanan dibandingkan teks. Gambar dapat meringkas data yang kompleks dengan cara yang baru. Kellerman (dalam Munir, 2012, hlm. 20) menjelaskan bahwa "Gambar dapat berbentuk garis (line drawing), bulatan, kotak, bayangan, warna, dan sebagainya yang dikembangkan dengan menggunakan perangkat lunak agar multimedia dapat disajikan dengan lebih menarik dan efektif". Gambar merupakan 
JOGED

ISSN: 1858-3989

saran yang tepat untuk menyampaikan informasi atau materi pelajaran, apalagi pada saat pendidik berorientasi pada gambar yang bentuknya visual. Peserta didik yang berorientasi pada media visual seperti gambar dan animasi akan lebih mudah memahami informasi atau materi pelajaran yang disampaikan pendidik dibandingkan dengan informasi yang didapat dalam bentuk teks.

4. Video

Video pada dasarnya alat suatu media yang dapat menunjukkan simulasi benda nyata berupa informasi atau materi pelajaran yang dengan lebih menarik, langsung, dan efektif. Hal tersebut merujuk pada pernyataan Agnew dan Kellerman (dalam Munir, 2012, hlm. 21) yang mendefinisikan bahwa "video sebagai media digital yang menunjukkan susunan atau urutan gambar-gambar bergerak dan dapat memberikan ilusi/fantasi". Video dalam multimedia digunakan untuk menggambarkan suatu kegiatan atau aksi. Video menyediakan sumber data yang kaya dan hidup bagi aplikasi multimedia.

\section{Animasi}

Animasi adalah suatu tampilan yang menggabungkan antara media teks, grafik, dan suara dalam suatu aktivitas pergerakan. Hal tersebut merujuk pada pernyataan Neo \& Neo (dalam Munir, 2012, hlm. 21) mendefinisikan "animasi sebagai satu teknologi yang dapat menjadikan gambar yang diam menjadi bergerak kelihatan seolah-olah gambar tersebut hidup, dapat bergerak, beraksi, dan berkata”. Dalam komputer animasi digunakan untuk menciptakan gerak pada layar. Multimedia animasi digunakan untuk menjelaskan dan menyimulasikan sesuatu yang sulit dilakukan melalui video.

6. Audio

Audio dapat meningkatkan daya ingat serta bisa membantu bagi pengguna yang kelemahan dalam penglihatan. Tanpa adanya audio/suara dalam sebuah multimedia maka hasilnya tidak lengkap. Sebagaimana menurut Munir (2012, hlm. 22) bahwa "audio didefinisikan sebagai macam-macam bunyi dalam bentuk digital seperti suara, musik, narasi dan sebagainya yang bisa didengar untuk keperluan suara latar, penyampaian pesan duka, sedih, semangat dan macammacam disesuaikan dengan situasi dan kondisi”. Suara atau audio di dalam multimedia berupa suara musik, suara dari voice record maupun efek-efek suara lain. Biasanya narasi ditampilkan bersama-sama dengan foto atau teks untuk lebih memperjelas informasi yang akan disampaikan.

7. Interaktivitas

Elemen interaktivitas sangat penting dalam multimedia interaktif. Elemen lain seperti teks, suara, video, dan foto dapat disampaikan di media lain seperti TV dan VCD player, tetapi elemen interaktif hanya 
dapat ditampilkan di komputer. Elemen ini sangat memanfaatkan kemampuan komputer sepenuhnya. Aspek interaktif dalam multimedia bisa berupa navigasi, simulasi, permainan, dan latihan. Hal tersebut merujuk pada pernyataan Munir (dalam Winaryono dan Setiawan, 2015, hlm. 3) bahwa "apabila dalam suatu aplikasi multimedia, pengguna diberikan suatu kemampuan mengontrol elemen yang ada, maka multimedia tersebut disebut multimedia interaktif".

Berkenaan uraian di atas dapat kita pahami bahwa dalam multimedia interaktif terdapat beberapa komponen yang membantu pengguna bernavigasi, berkarya, berinteraksi, dan berkomunikasi. Tanpa adanya elemen tersebut maka informasi yang diberikan menjadi kurang menarik (membosankan) bagi siswa. Selain itu, komponen tersebut juga dapat memperkuat informasi yang telah didapatkan.

Spesifikasi produk yang diharapkan pada Multimedia Tari Kreasi Anak "Orayorayan" untuk pembelajaran SBdP di Sekolah Dasar meliputi:

1. Produk dapat digunakan pada pembelajaran Tematik untuk siswa kelas IV di Sekolah Dasar.

2. Produk digunakan pada pembelajaran Tematik dengan tema 8 "Daerah Tempat Tinggalku”, Subtema 2 "Keunikan Daerah Tempat Tinggalku, Pembelajaran 6.

3. Produk berupa Multimedia Tari Kreasi
Anak "Oray-orayan" mampu digunakan dengan mudah, praktis, efektif, dan edukatif.

Berikut merupakan penjabaran desain (design principle) Multimedia Tari Kreasi Anak “Oray orayan" untuk pembelajaran SBdP di Sekolah Dasar berdasarkan proses FGD yang dilakukan.

Peneliti melakukan identifikasi prinsip desain yang digunakan dalam pengembangan media pembelajaran. Penjabaran prinsip desain yang dilakukan dalam melakukan Multimedia Tari Kreasi Anak "Oray-orayan" untuk pembelajaran SBdP di antaranya:

1. Model/ Bentuk Multimedia

Model/ bentuk multimedia yang dibuat berupa video pembelajaran yang di distribusikan melalui Digital Versatile Disc (DVD).

2. Tujuan Multimedia

Tujuan mengembangkan Multimedia Tari Kreasi Anak "Oray-orayan" adalah untuk mempermudah siswa dalam memahami materi pembelajaran SBdP sehingga mencapai tujuan pembelajaran baik secara kognitif, afektif, maupun psikomotor pada siswa kelas IV (Surjono, Herman Dwi, 2017, hlm. 3).

\section{Konteks Multimedia}

Multimedia Tari Kreasi Anak "Oray-orayan" untuk pembelajaran SBdP dikembangkan untuk melengkapi proses pembelajaran di kelas IV Sekolah Dasar. Pembelajaran ini diimplementasikan pada pembelajaran SBdP. 
Konsep yang diterapkan dalam Multimedia Tari Kreasi Anak "Oray-orayan” yaitu mengenal gerak tari kreasi anak "Orayorayan" dan meragakan gerak tari kreasi anak “Oray-orayan". Dalam konsepan tersebut mencakup 3 aspek dalam pembelajaran di antaranya (a) kognitif yaitu mengetahui tari kreasi, mengetahui gerakan-gerakan tari kreasi dan mengetahui iringan lagu, (b) afektif yaitu ketepatan gerakan dengan iringan gerak tari kreasi anak "Oray-orayan" dan (c) sikap yaitu tingkah laku siswa dalam proses pembelajaran tari (Subekti Ari, 2016 hlm. 152)

\section{Karakteristik Multimedia}

Karakteristik pengembangan Multimedia Tari Kreasi Anak "Oray-orayan" memperhatikan Kompetensi Dasar (KD) dan Indikator Pencapaian Kompetensi (IPK) yang dipilih. KD dan IPKN tersebut di antaranya sebagai berikut:

a. Kompetensi Dasar dan Indikator Pencapaian Kompetensi

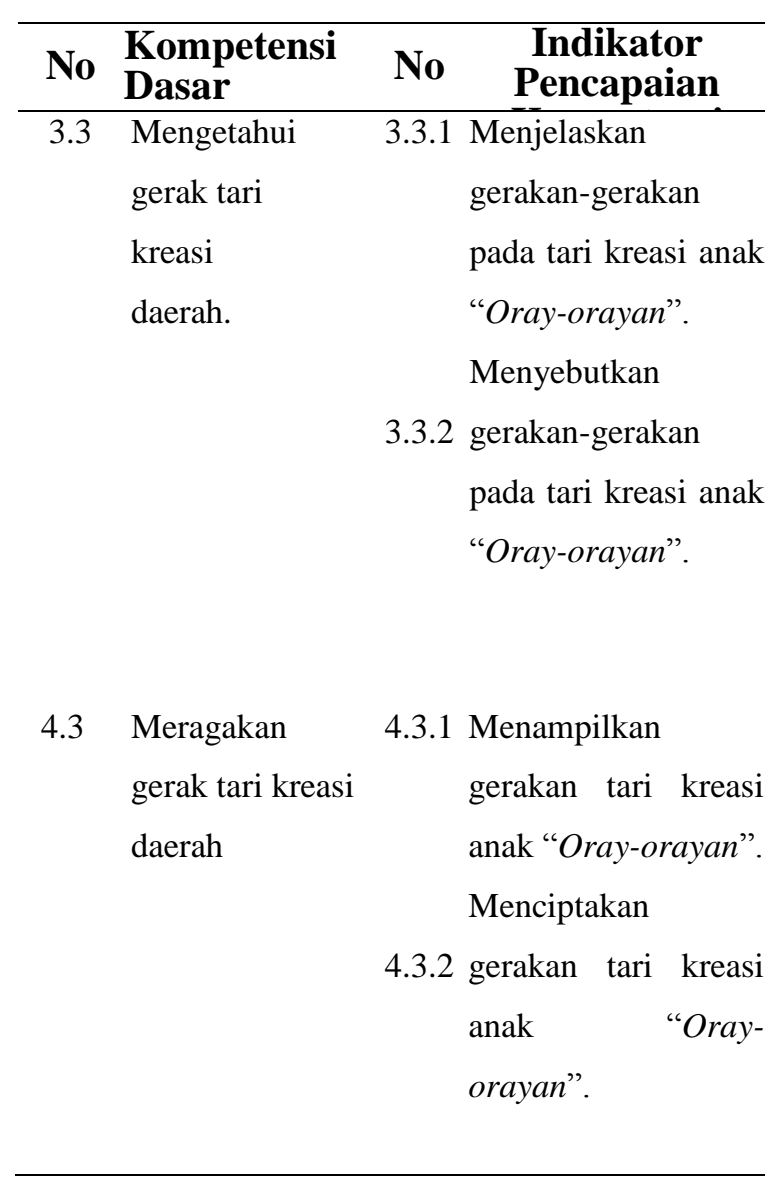

Tabel. 1 Kompetensi Dasar dan Indikator Pencapaian Kompetensi

b. Tujuan Pembelajaran

1) Melalui tayangan video, siswa dapat Menjelaskan gerakan-gerakan pada tari kreasi anak "Oray-orayan" dengan benar.

2) Melalui tanya jawab, siswa dapat menyebutkan gerakan-gerakan pada tari kreasi anak "Oray-orayan" dengan benar.

3) Melalui penugasan memperagakan tari kreasi anak "Oray-orayan", siswa dapat menampilkan gerakan tari kreasi anak "Oray-orayan" dengan baik dan benar. 
4) Melalui penugasan memperagakan tari kreasi anak "Oray-orayan", siswa dapat menciptakan gerakan tari kreasi anak "Oray-orayan" dengan baik dan benar.

c. Materi Pembelajaran

Materi pembelajarannya adalah gerak tari kreasi.

d. Karakter yang dikembangkan

Karakter yang dikembangkan dalam multimedia ini adalah mengutamakan aspek isi atau materi, aspek instruktural dan aspek tampilan.

\section{Prosedur Media}

a. Pembuatan Flowchart

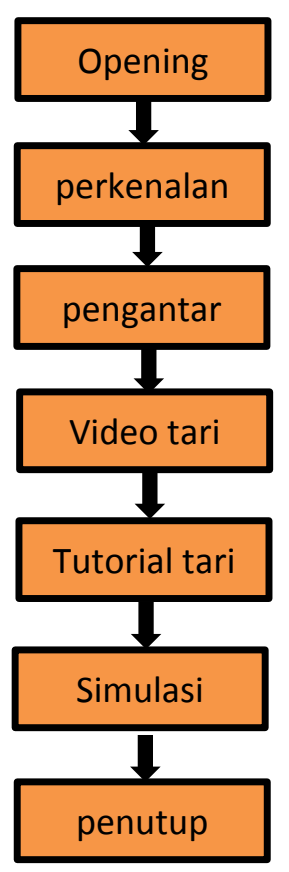

Gambar 2. Flowchart Rencana Multimedia Tari Kreasi Anak "Oray-orayan" b. Pembuatan Storyboard

\begin{tabular}{|l|l|l|l|}
\hline Scene No. & 1 & Shoot No. & 1 \\
\hline \multicolumn{2}{|l|}{} \\
\hline \multicolumn{1}{|l|}{} \\
\end{tabular}

\begin{tabular}{l} 
Scene No. 2 Shoot No. \\
\hline
\end{tabular}




\begin{tabular}{|l|l|l|l|}
\hline Scene No. & 3 & Shoot No. & 3 \\
\hline & \\
& \\
& \\
& \\
& \\
\hline
\end{tabular}

\begin{tabular}{|l|l|l|l|}
\hline Scene No. & 4 & Shoot No. & 4 \\
\hline \multicolumn{1}{|c|}{} \\
\cline { 1 - 1 }
\end{tabular}

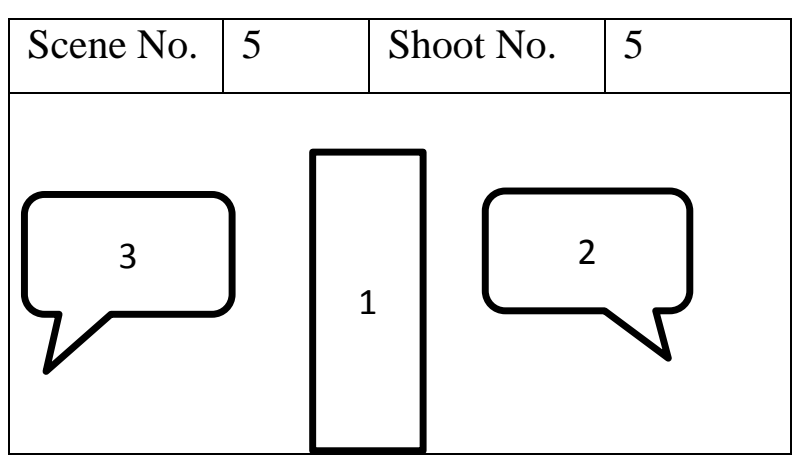

Keterangan :

1. Tutor

2. Teks pertanyaan

Naah... ada yang sudah tau belum tari kreasi itu bagaimana?

3. Teks pertanyaan

Atau... mengapa sih kak namanya tari kreasi "Oray-orayan"?

Penjelasan :

Tutor menyebutkan pertanyaan-pertanyaan mengenai materi.

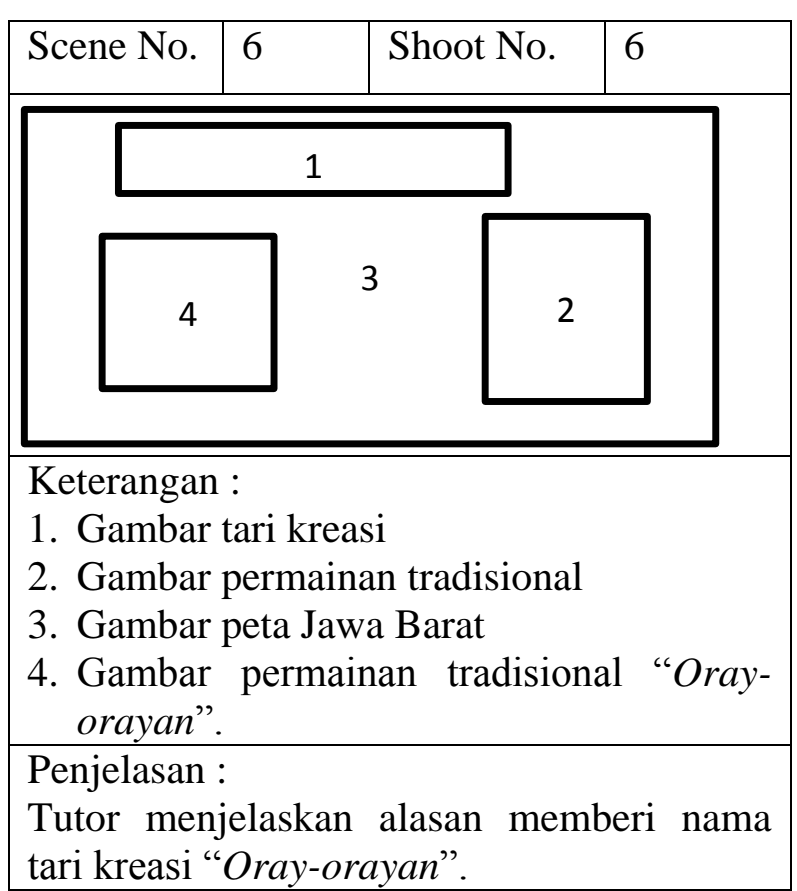

\begin{tabular}{|l|l|l|l|}
\hline Scene No. & 7 & Shoot No. & 7 \\
\hline & & \\
\hline
\end{tabular}




\begin{tabular}{|l|l|l|l|}
\hline Scene No. & 8 & Shoot No. & 8 \\
\hline & \\
\hline & \\
\hline
\end{tabular}

\begin{tabular}{|l|l|l|l|}
\hline Scene No. & 9 & Shoot No. & 9 \\
\hline & \\
& \\
\end{tabular}

\begin{tabular}{|l|l|l|l|}
\hline Scene No. & 10 & Shoot No. & 10 \\
\hline & & \\
\hline
\end{tabular}

"Oray-orayan".

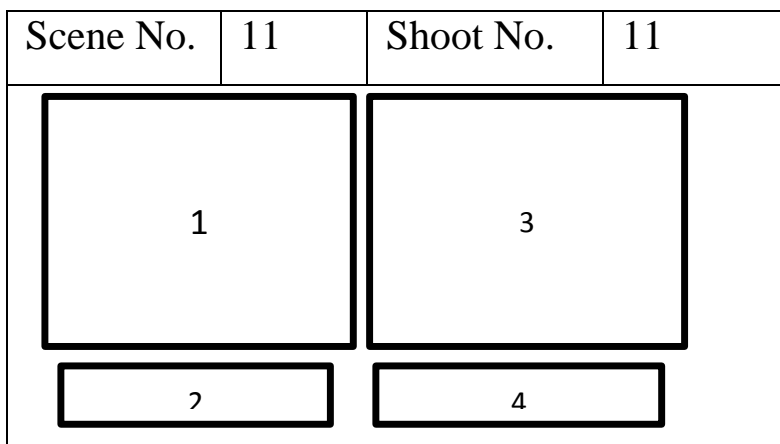

Keterangan :

1. Video Penari

2. Teks : Tampak Depan

3. Video Penari

4. Teks : Tampak Belakang

Penjelasan :

Tutorial tari kreasi anak "Oray-orayan".

\begin{tabular}{|l|l|l|l|}
\hline Scene No. & 12 & Shoot No. & 12 \\
\hline & & \\
\end{tabular}




\begin{tabular}{|l|l|l|l|}
\hline Scene No. & 13 & Shoot No. & 13 \\
\hline 2 & 1 \\
\hline
\end{tabular}

\begin{tabular}{|l|l|l|l|}
\hline Scene No. & 14 & Shoot No. & 14 \\
\hline & 1 \\
& \\
& \\
\hline
\end{tabular}

\begin{tabular}{|l|l|l|l|}
\hline Scene No. & 15 & Shoot No. & 15 \\
\hline & & \\
\hline & & \\
\hline
\end{tabular}

\begin{tabular}{|c|c|c|c|}
\hline Scene No. & 16 & Shoot No. & 16 \\
\hline \multicolumn{3}{|c|}{1} & \\
\hline \multicolumn{4}{|c|}{$\begin{array}{l}\text { Keterangan : } \\
\text { 1. Teks ucapan terimakasih }\end{array}$} \\
\hline \multicolumn{4}{|c|}{$\begin{array}{l}\text { Penjelasan: } \\
\text { Menayangkan ucapan terimakasih yang } \\
\text { sebesar-besarnya kepada pihak yang terlibat } \\
\text { dalam produk multimedia tari kreasi "Oray- } \\
\text { orayan" ini. }\end{array}$} \\
\hline
\end{tabular}

Tabel 2. Storyboard Multimedia Tari Kreasi Anak "Oray-orayan"

c. Proses Garapan Tari

1) Eksplorasi gerakan tari

Eksplorasi yang dilakukan dengan mengamati kejadian nyata yang berada di lingkungan sekitar yaitu permainan tradisional "Oray-orayan".

2) Improvisasi gerak tari

Improvisasi yang dilakukan adalah menentukan gerakan tari, menentukan tipe tari dan menentukan cara penyajian pada tari kreasi "Oray-orayan".

3) Komposisi

Pada tahap komposisi ini menjadi proses kreativitas mendalam di antaranya menghayati tarian, merasakan, memberi bentuk tarian, dan akhir tarian.

4) Evaluasi

Evaluasi pada tarian berfokus pada aspek 
perubahan dan penghalusan dalam

konstruksi desain ruang dan desain waktu pada tarian.

d. Unsur Pendukung Tari

1) Tata Rias

Tata rias dalam tari kreasi anak "Orayorayan" ini adalah tata rias yang natural sesuai dengan umur anak sekolah dasar dan sesuai dengan tema tariannya.

2) Tata Busana

Tata busana yang digunakan pada tari tari kreasi anak "Oray-orayan" ini adalah menggunakan kain batik dan kain polos tanpa dijahit. Pengaplikasiannya kain tanpa dijahit ini dinamakan drafing.

3) Aksesoris

Aksesoris yang digunakan adalah bordir bunga, yang diaplikasikan di sebelah kanan kepala.

4) Musik Tari

Musik yang digunakan berjudul orayorayan. Musik didapat dari youtube dengan link https://youtu.be/1HWs5VZiv0A.

(Esapoetra, 2013). e. Pola Lantai

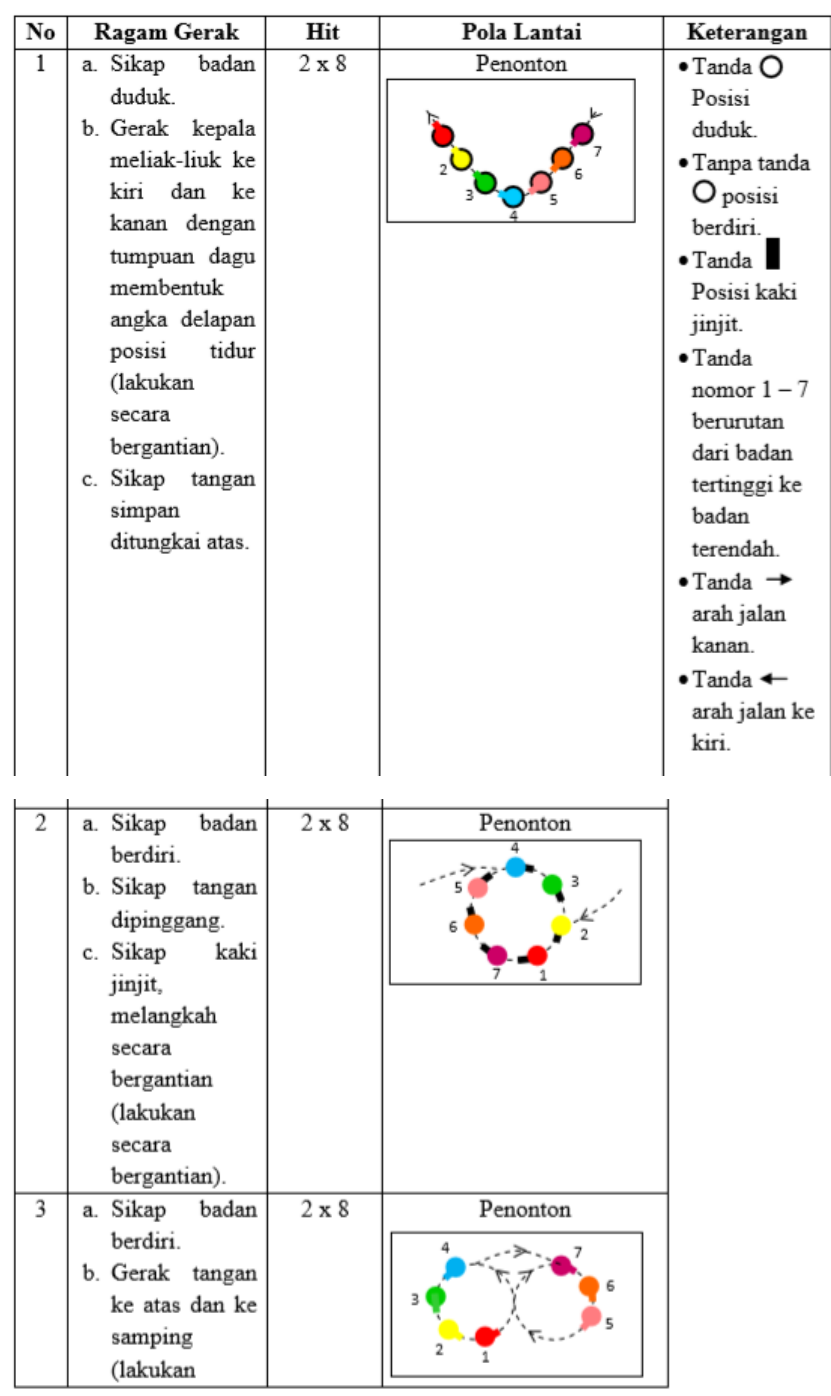

\begin{tabular}{|c|}
\hline $\begin{array}{l}\text { secara } \\
\text { bergantian). } \\
\text { Sikap kaki } \\
\text { gedug, } \\
\text { melangkah } \\
\text { secara } \\
\text { bergantian } \\
\text { dengan } \\
\text { tumpuan ujung } \\
\text { tumit (lakukan } \\
\text { secara } \\
\text { bergantian). }\end{array}$ \\
\hline
\end{tabular}


JOGED

ISSN: $1858-3989$
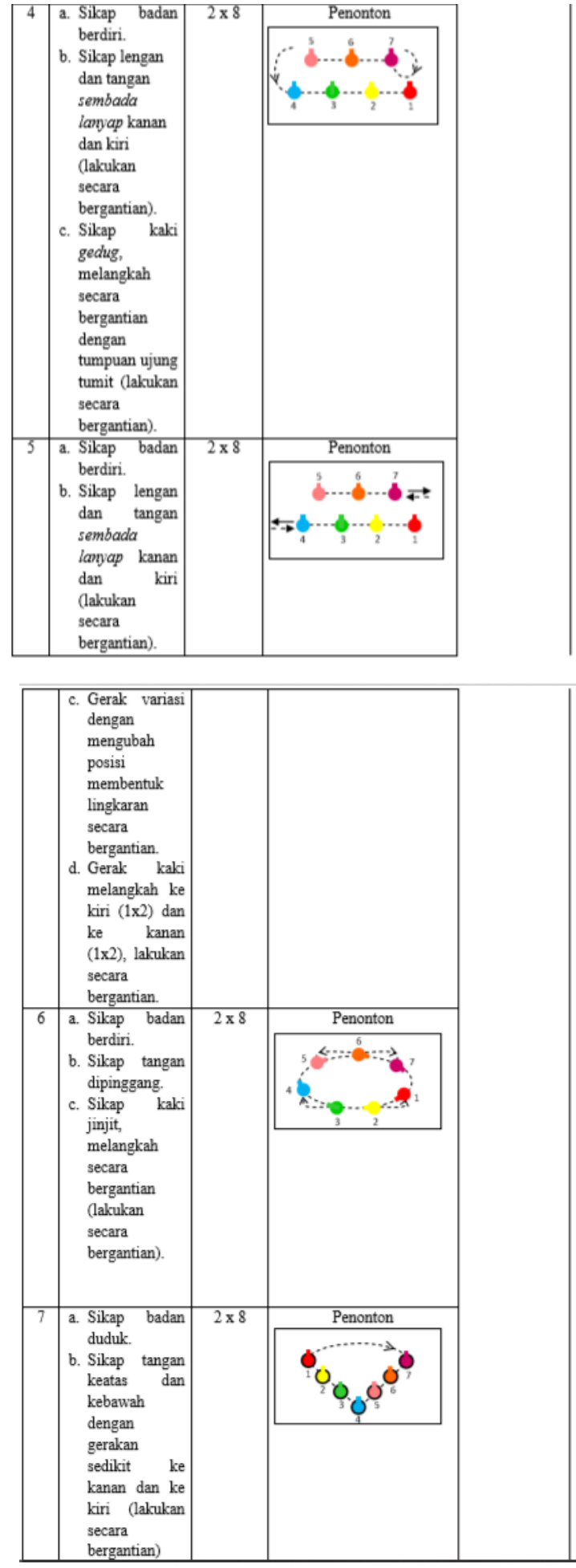
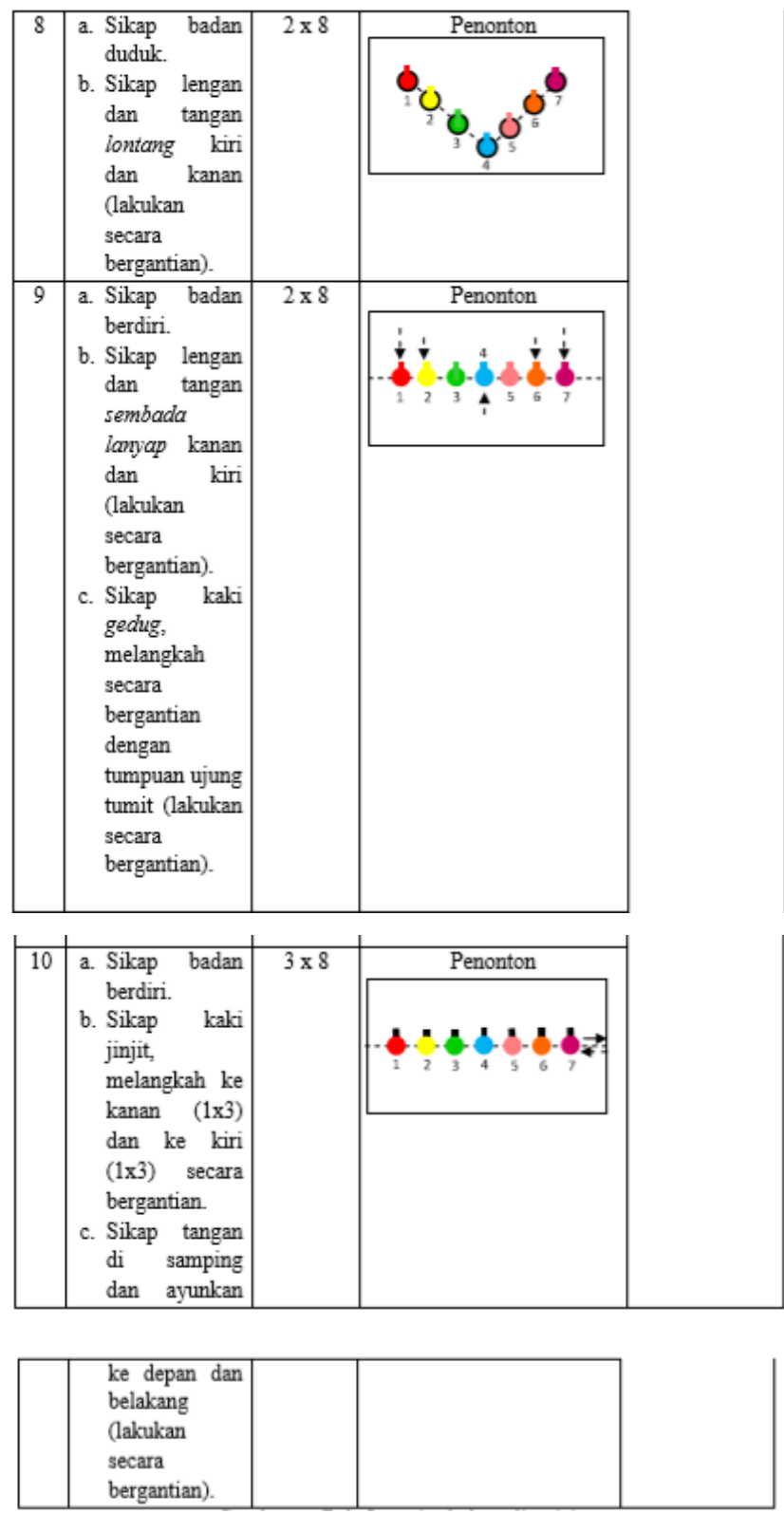

Tabel 3. Pola Lantai Tari Kreasi Anak "Oray-orayan"

\section{f. Editing video}

\section{1) Wondershare Filmora}

Pada filmora ini memiliki fitur lengkap dan mudah digunakan untuk editing pemula selain itu kelebihan dari filmora ini pengoprasiannya sangat mudah, banyak efek yang tersedia, aplikasinya ringan, efek visual dinamis dan lain sebagainya (Lestari W.A., 
2019). Berikut tampilan aplikasi wondershare

filmora:

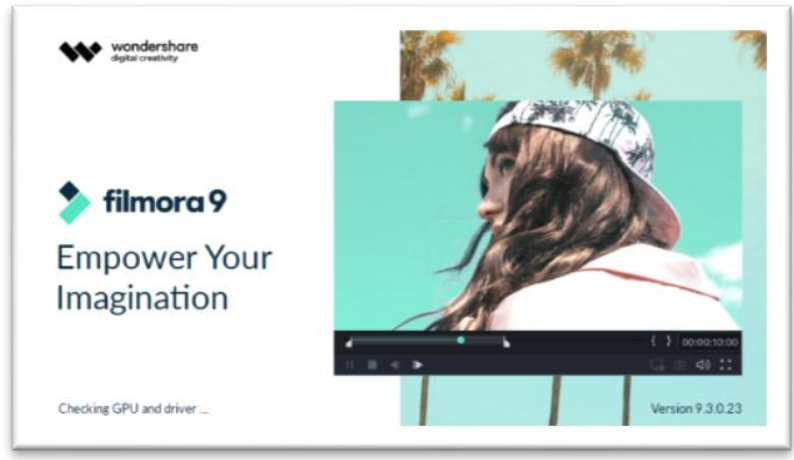

Gambar 3. Wondershare Filmora

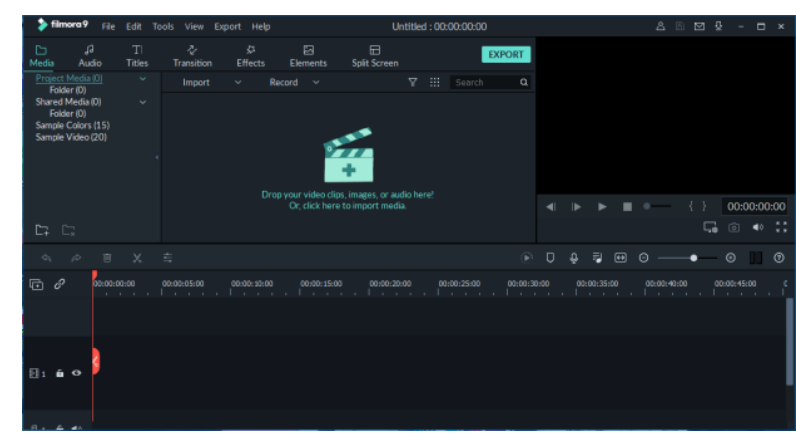

Gambar 4. Tampilan Wondershare Filmora

\section{2) Microsoft PowerPoint}

Microsoft PowerPoint merupakan perangkat lunak untuk membuat sajian visual yang dapat menginterpretasikan berbagai media, seperti video, animasi, gambar dan suara. Dalam aplikasi ini terdapat menumenu memungkinkan pengguna untuk membuat dan mengembangkan media pembelajaran lebih menarik dan menyenangkan (Yusri Radhya \& Husain Al., 2017). Berikut tampilan aplikasi Microsoft PowerPoint:

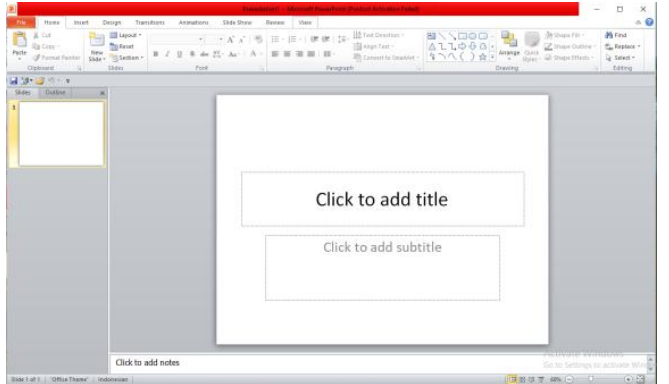

Gambar 5. Microsoft PowerPoint 2010

g. Desain cover DVD media
pembelajaran
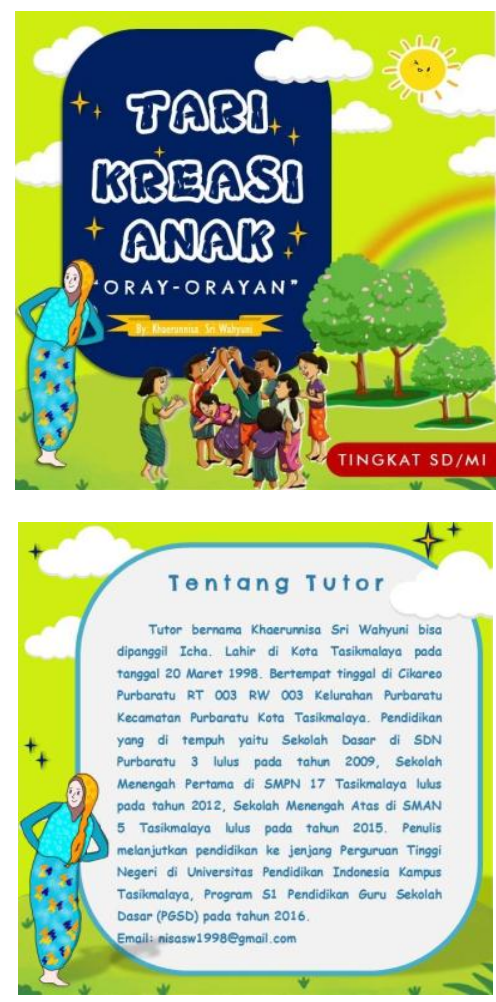

Gambar 6. Cover DVD Video Tari Kreasi Anak "Oray-orayan"

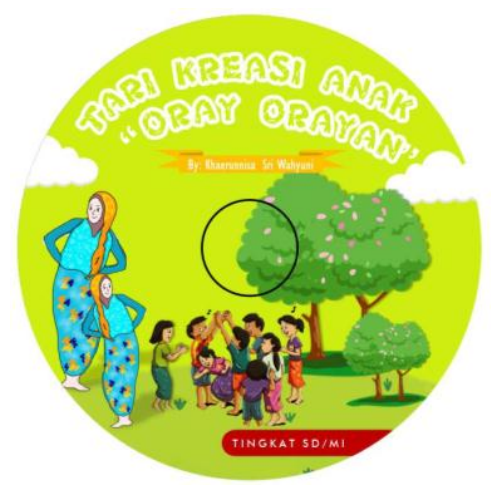

Gambar 7. Label DVD Video Tari Kreasi Anak "Orav-oravan" 


\section{PENUTUP}

Dapat disimpulkan bahwa rancangan multimedia tari kreasi anak "Oray-orayan" sangat penting agar tercapainya tujuan yaitu mengembangkan media pembelajaran untuk pembelajaran SBdP di Sekolah Dasar. Media ini telah mendapatkan masukan dan penilaian sesuai dengan aspek yang diharapkan agar dapat digunakan untuk perangkat pembelajaran di Sekolah Dasar.

\section{DAFTAR SUMBER ACUAN}

$\begin{array}{ccc}\text { Ashyar, } \quad \begin{array}{lll}\text { Rayandra. } \\ \text { Mengembangkan }\end{array} & \text { 2011. } & \text { Kreatif } \\ \begin{array}{l}\text { Pembelajaran. } \\ \text { Persada (GP) Press. }\end{array} & \text { Jakarta: } & \text { Gedia } \\ & \end{array}$

Giyartini Rosarina. 2014. "Makna Simbolik Kaulinan Barudak Oray-orayan". Vol.24 (No.4), 377-386.

Kementrian Pendidikan dan Kebudayaan Revisi. 2016. Silabus Mata Pelajaran Sekolah Dasar/ Madrasah Ibtidaiyah (Sekolah Dasar/MI). Jakarta.

Lestari Asti Tri. 2017. Pembelajaran Tari Kreatif melalui Kaulinan Budak Lembur di Sekolah Dasar. Naturalistic: Jurnal Kajian Penelitian Pendidikan dan Pembelajaran, Vol.1(No.2), 102-111.

Lestari W.A., dkk. 2019. Media Pembelajaran Interaktif Enkripsi Caesar Ciher Vigenere Cipher dan Algoritma RSA. E-Proceeding of Applied Science, Vol.5(No.3), 2912-2924.

Lidinillah, D. A. M. (2012). Educational Design Research: a Theoretical Framework for Action. Universitas Pendidikan Indonesia-Kampus Tasikmalaya.

Munir, 2013. Multimedia: Konsep \& Aplikasi dalam Pendidikan. Bandung: Alfabeta

Plomp. 2007. "Educational Design Research : An Introduction", dalam An Introduction to Educational
Research. Enschede, Netherland : National Institute for Curriculum Development

Sugiyono. 2012. Metode Penelitian Kuantitatif, Kualitatif dan $R \& D$. Bandung: Alfabeta.

Sugiyono. 2013. Metode Penelitian Kuantitatif, Kualitatif dan $R \& D$. Bandung: Alfabeta.

Surjono Herman Dwi . 2017. Multimedia Pembelaaran Interaktif. Yogyakarta: UNY Press.

Subekti Ari. 2016. Tema 8 Daerah Tempat Tinggalku. Jakarta: Kementrian Pendidikan dan Kebudayaan.

Yusri Radhya \& Husain Al. Pengembangan Multimedia Interaktif Menggunakan Microsoft Power Point Dalam Pembelajaran Matematika Kelas X MA KM Muhammadiyah Padang Panjang. Jurnal Ipteks Terapan: Research of Applied Science and Education, Vol. 11(No.1), 1-8.

Subekti, Ari. 2016. Daerah Tempat Tinggalku. Jakarta: Kementrian Pendidikan dan Kebudayaan.

Sugiyono. 2012. Metode Penelitian Kuantitatif, Kualitatif dan $R \& D$. Bandung: Alfabeta.

2013. Metode Penelitian Kuantitatif, Kualitatif dan $R$ \& $D$. Bandung: Alfabeta. 